\title{
Effects of two different types of physics learning on the results of CLASS test
}

\author{
Mirko Marušić ${ }^{1}$ and Josip Sliško ${ }^{2}$ \\ ${ }^{1}$ I. Gimnazija, Split, Croatia \\ ${ }^{2}$ Facultad de Ciencias Físico Matemáticas, Benemérita Universidad Autónoma de Puebla, Puebla, México
}

(Received 14 January 2011; published 15 February 2012)

\begin{abstract}
During a one-semester-long research project with high school students, we deployed and gauged efficiency of two different reform teaching methods: reading, presenting, and questioning (RPQ) and experimenting and discussion (ED). In this paper we report on changes in students' attitudes and beliefs about physics and learning physics. We used the Colorado Learning Attitudes about Science Survey (CLASS v3) to assess the relative effectiveness of the two methods. The data show that both methods improved student attitudes and beliefs but to different extents. The RPQ group (91 students) achieved an overall improvement of $+5.8 \%$ in attitudes and beliefs, while the ED group ( 85 students) attained an improvement of $+25.6 \%$. These results suggest that both methods may have a substantial potential for improving students' attitudes and beliefs about physics and physics learning, with the ED method being more promising than the RPQ. method
\end{abstract}

DOI: 10.1103/PhysRevSTPER.8.010107

PACS numbers: 01.40.Di, 01.40.ek, 01.40.Fk, 01.40.Ha

\section{INTRODUCTION}

In the past decade, the physics education research community has started looking much closer into students' epistemological beliefs about physics knowledge and physics learning [1-3]. Several assessment instruments have been developed in order to determine and evaluate students' beliefs about how physics as science works and how physics should be learned.

Four well-known surveys for probing student beliefs about the physical sciences and their learning are the Maryland Physics Expectation survey (MPEX) [4], the Views About Science Survey (VASS) [5], the Epistemological Beliefs Assessment about Physical Science (EBAPS) [6], and the Colorado Learning Attitudes about Science Survey (CLASS) [7-9].

Each one of the four surveys focuses on a specific aspect of epistemological beliefs or expectations. Also, some focus on breadth while others delve into a limited number of ideas in depth. There are also several other nature of science surveys, such as Views of Nature of Science (VNOS) [10].

It is widely reported that students' beliefs differ from those shared among experts [8,10-12]. For instance, experts see physics as a coherent framework of concepts which describe and explain natural physical phenomena. Novices, on the other hand, frequently see physics as an arbitrary collection of isolated pieces of information that are handed down by authority (e.g., teacher or textbook author). To a novice, laws and concepts in physics may

Published by the American Physical Society under the terms of the Creative Commons Attribution 3.0 License. Further distribution of this work must maintain attribution to the author(s) and the published article's title, journal citation, and DOI. have no clear connection to the real world. Accordingly, they may perceive them as best learned by memorization.

Redish et al. [4] found students' overall MPEX scores deteriorated rather than becoming more expertlike during a period of one semester of introductory physics. Even students enrolled in courses that use research-based curricula and get significant conceptual gains measured by conceptual instruments such as the Force and Motion Conceptual Evaluation (FMCE) [13] commonly do not show desired increases in beliefs about aspects of the nature of learning science, as measured by the MPEX or the CLASS [12]. In fact, some of these courses even show negative CLASS shifts [14]. These results suggest that conceptual learning is not necessarily associated with the development of expertlike thinking about the nature of scientific knowledge and science learning. These results are in resonance with findings that even considerable gains in conceptual knowledge do not lead to improvement of scientific reasoning [15].

Hrepic et al. [16] studied effects of an inquiry-based curriculum [Operation Primary Physical Science (OPPS)] targeting preservice elementary teachers, both from a conceptual and an attitudinal perspective. While significant conceptual gains were found using a conceptual instrument designed by curriculum developers, only very small positive shifts in attitudes about science and the nature of science learning were measured by the CLASS. The same curriculum was used in two different semesters. While in one semester there was a consistent improvement in all the categories, this was not the case in another semester. This means that there was no gain but there was no decrease either, and by CLASS standards, that is already a success. Although the OPPS curriculum was developed for preservice elementary teachers, it may not explicitly address issues about science learning and the nature of science knowledge. 
Mamolo and Rebello [17] also studied results of a research-based curriculum designed specifically for preservice elementary teachers. Students in this learningcycle-based course were given both the EBAPS [6] and the VNOS [18] surveys. Neither survey showed significant shifts in students' overall scores on these instruments, although the EBAPS showed a small positive shift in the real-life applicability category while the VNOS revealed a small positive shift in the inferential nature of scientific models.

Otero and Gray have published positive results on the CLASS from courses with preservice teachers utilizing the Physics and Everyday Thinking (PET) curriculum (shifts toward expert responses ranged from $+4 \%$ to $+16.5 \%$ ) which includes an explicit nature of science theme [19]. Positive effects on CLASS results have also been observed in courses based on modeling instruction [20].

While previous studies examined the relation between student interest and future career prospects, retention, and student beliefs, more recent ones have started looking at correlations between students' beliefs and other factors, such as content learning or choice of major [11].

The goal of the present research was to explore how two different reform teaching methods, reading, presenting, and questioning (RPQ) and experimenting and discussion (ED), affect students' attitudes and beliefs about physics and physics learning as measured by the CLASS survey.

\section{STUDY DESIGN}

\section{A. General information about students and curriculum}

This research was conducted with six complete physics sections of senior students (17-18 years) in the last (12th) grade of a high school in Split (Croatia) during Spring semester of 2009. This period is particularly suitable for conducting the project because the students are in the last semester of their high school education and already familiar with the content of different scientific areas. Having been exposed to physics, chemistry, and biology as separate subjects since the seventh grade, they can also be expected to have formed personal attitudes towards them. All the courses involved in the project were taught by the same instructor (first author) who also administered all the research related probes and surveys. The total number of students was 176. They were all enrolled in classical college-prep programs that emphasized languages (grammar and modern languages curriculums). Although the curriculums are language oriented, they give students a solid foundation to proceed and pursue a broad spectrum of different majors at the university level, from humanities to scientific and technical studies. In the Republic of Croatia there is no major difference between different college-prep high school curriculums (called gymnasiums) in this respect, as all these schools try to prepare students for a vast area of university study programs. That way, students are given the opportunity to explore options and determine their primary field(s) of interest during their stay at the high school. Table I shows the language-oriented curriculums for high schools in the Republic of Croatia.

Among the other college-prep schools, the school in which the research has been carried out is the one that accepts only the best students, i.e., those with the best grades gained in elementary schools. Thus, in this school there are a negligible number of students with learning or behavioral problems. From the time they enter high school these students know that upon graduation they will most likely continue their studies at higher education institutions. It is interesting to note that, although this is a school with grammar and modern languages oriented curriculum (Table I), many of the students still choose to pursue education in some scientific, technical, or medical study programs.

The grammar program is characterized by studying two classical languages, Latin and old Greek, while the modern languages program is characterized by active learning of at least two live foreign languages (typically English, Italian, German, French, Spanish, etc.), out of which English is obligatory and the selection of the other one is left to student preference. Mathematics is, besides Croatian and a foreign language, the basic subject of any high school program in Croatia. It is studied throughout high school; i.e., in all four years, the grammar program consists of four 45-min lessons a week in the first two years and three lessons a week in the last two years. In the modern languages oriented program, it amounts to three lessons a week in all four years. Mathematics topics typically include extensive algebra and trigonometry with differential and integral calculus normally covered in the last year.

Both programs also include physics, chemistry, and biology in all four years, two lessons a week for each of the mentioned subjects. Also, all students are enrolled in high schools with some preknowledge of the abovementioned subjects because these are already introduced in the two final years of primary school (7th and 8th grade) education (each through two lessons a week, mandatory in all schools across the country). Consequently, all students included in the research had been in their sixth year of studying physics within their mandatory and chosen educational path.

The high school program in grammar and modern languages oriented programs also includes subjects such as psychology, sociology, logic, and philosophy. For this reason, when conducting the project, the instructor did not choose to pay special attention to the topics from the nature of science. Since the research was carried out in the last semester of the students' high school education, we could assume that they all had some knowledge concerning those areas which can help create some attitudes and beliefs towards nature of science.

Understanding of the nature of science refers to the epistemiology of science and includes seven basic aspects 
TABLE I. Syllabus in the grammar school and modern languages oriented high school.

\begin{tabular}{|c|c|c|c|c|c|c|c|c|}
\hline \multirow[b]{2}{*}{ Subject } & \multicolumn{4}{|c|}{$\begin{array}{c}\text { Grammar curriculum } \\
\text { Year }\end{array}$} & \multicolumn{4}{|c|}{$\begin{array}{c}\text { Modern languages curriculum } \\
\text { Year }\end{array}$} \\
\hline & I & II & III & IV & I & II & III & IV \\
\hline Croatian language and literature & 4 & 4 & 4 & 4 & 4 & 4 & 4 & 4 \\
\hline First foreign language (English) & 3 & 3 & 3 & 3 & 4 & 4 & 4 & 4 \\
\hline Second foreign language & a & a & a & a & 4 & 3 & 3 & 3 \\
\hline Third foreign language & $\cdots$ & $\cdots$ & $\cdots$ & $\cdots$ & $\mathrm{b}$ & $\mathrm{b}$ & $\mathrm{b}$ & $\mathrm{b}$ \\
\hline Latin & 3 & 3 & 3 & 3 & 2 & 2 & $\cdots$ & $\cdots$ \\
\hline Greek & 3 & 3 & 3 & 3 & $\cdots$ & $\cdots$ & $\cdots$ & $\cdots$ \\
\hline Music & 1 & 1 & 1 & 1 & 1 & 1 & 1 & 1 \\
\hline Arts & 1 & 1 & 1 & 1 & 1 & 1 & 1 & 1 \\
\hline Psychology & $\cdots$ & $\cdots$ & 2 & $\cdots$ & $\cdots$ & $\cdots$ & 2 & $\cdots$ \\
\hline Logic & $\cdots$ & $\cdots$ & 1 & $\cdots$ & $\cdots$ & $\cdots$ & 1 & $\cdots$ \\
\hline Philosophy & $\ldots$ & $\ldots$ & $\ldots$ & 2 & $\cdots$ & $\cdots$ & $\cdots$ & 2 \\
\hline Sociology & $\cdots$ & $\cdots$ & 2 & $\cdots$ & $\cdots$ & $\cdots$ & 2 & $\cdots$ \\
\hline History & 2 & 2 & 2 & 2 & 2 & 2 & 2 & 2 \\
\hline Geography & 2 & 2 & 1 & 2 & 2 & 2 & 1 & 2 \\
\hline Mathematics & 4 & 4 & 3 & 3 & 3 & 3 & 3 & 3 \\
\hline Physics & 2 & 2 & 2 & 2 & 2 & 2 & 2 & 2 \\
\hline Chemistry & 2 & 2 & 2 & 2 & 2 & 2 & 2 & 2 \\
\hline Biology & 2 & 2 & 2 & 2 & 2 & 2 & 2 & 2 \\
\hline Information technology & $\cdots$ & 2 & $\cdots$ & $\cdots$ & $\cdots$ & 2 & $\cdots$ & $\cdots$ \\
\hline Politics and economics & $\cdots$ & $\cdots$ & $\cdots$ & 1 & $\cdots$ & $\cdots$ & $\cdots$ & 1 \\
\hline Physical education & 2 & 2 & 2 & 2 & 2 & 2 & 2 & 2 \\
\hline Religion or ethics & 1 & 1 & 1 & 1 & 1 & 1 & 1 & 1 \\
\hline
\end{tabular}

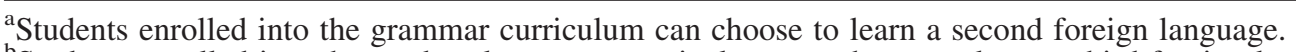

${ }^{\mathrm{b}}$ Students enrolled into the modern languages curriculum can choose to learn a third foreign language.

agreed on by the experts on education, philosophers, and sociologists of science. These are all implemented in the high school system. The studied literature $[21,10]$ indicates as basic the following aspects found as constituent parts of the curriculum of some high school subjects in the Croatian gymnasium program (mentioned in parentheses):

- changeability of scientific knowledge (philosophy),

- difference between perceiving and reasoning (psychology),

- cultural and social embeddedness of scientific knowledge (sociology),

- the myth of "scientific method" (logic, philosophy),

- creative and imaginative nature of scientific knowledge (logic, psychology),

- scientific theories and laws (logic),
- subjectivity and objectivity of science (logic, philosophy).

To understand the background of our study, it is important to know that the physics high school program (Table II) is the same for grammar and modern languages oriented programs and is as follows.

The research on the present reform teaching methods took one (Spring) semester and was carried out with two groups of students. Both groups studied the topics that are set by the annual syllabus [22].

Within the obligatory physics curriculum, there is some time, limited to one 45-min session per week, allocated to the free topic exploration. This means that, apart from the topics set by the syllabus, the teacher is allowed to introduce some additional content that may reflect their and/or

TABLE II. Physics high school program in grammar and modern languages.

\begin{tabular}{ll}
\hline \hline Academic year & Contents \\
\hline I & Motion, force, complex motion, energy and power, the general law of gravity, fluid mechanics \\
II & Temperature and thermal expansion, gas laws, molecular-kinetic theory of gases, internal energy, \\
& thermodynamics, electric charge, electricity, magnetic field \\
III & Oscillations, waves, geometric optics, wave optics, relativity \\
IV & Wave-particle properties of electromagnetic radiation, atoms, atomic nuclei and elementary particles, space, \\
& semiconductors, deterministic chaos \\
\hline \hline
\end{tabular}


the students' interests. This free topic time was the time used for the research. In other words, a total number of 16 45-min sessions (during the 16-week period) were at the teacher's disposal for the project. These included 12 sessions for treating the chosen topics and 4 sessions for pre- and postassessments (by the CLASS survey). The topics were chosen by researchers.

In agreement with the state educational advisor for physics, permission for the project was obtained. The permission allowed the instructor to use one lesson (45 min) out of two per week for the project, staying within the range of physics topics of the curriculum for the second semester of the Secondary 4 (space, semiconductors, and deterministic chaos).

\section{B. Two different pedagogical methods}

\section{Reading, presenting, and questioning}

RPQ pedagogy was utilized for a group of students (91 students) who were further broken down into three sections each with a specific task. Explored topics were related to the recent scientific discoveries in physics in the following way:

(i) students' autonomous reading or study of popular articles suggested by the teacher-researcher,

(ii) reading or study of online resources, some mandatory and some discovered by the students themselves in cyberspace,

(iii) students' presentations of the learning results in PowerPoint ${ }^{\mathrm{TM}}$ format,

(iv) students' questioning about unclear elements of reading and peer-presented materials.

The rationale behind this design was derived from apparently successful practices such as "read to learn" [23,24], "present to learn" [25,26], and "question to learn" [27-29].

Two examples were chosen to illustrate the ways in which modern science has been advancing new knowledge.

(1) Large Hadron Collider (LHC) at CERN.-One huge experiment, compact muon solenoid (CMS), was studied in detail along with its scientific potential and technologies developed for that purpose.

(2) Wilkinson microwave anisotropic probe (WMAP).-A detailed analysis was performed of how the experiment was conducted, how data were organized, and what were the major findings, along with mentioning other experiments that confirmed the results of WMAP (e.g., method supernova Ia).

This teaching design also involved breaking down each section into three different teams, with the purpose of encouraging discussion and further analysis of suggested contemporary physics topics.

In each section, three teams were formed for the following tasks:

(a) presenting the problems and questions that arise from the first topic (LHC), (b) presenting the problems and questions that arise from the second topic (WMAP),

(c) critically analyzing and evaluating reading materials and questioning the peers who were presenters.

The students chose the teams themselves, depending on their interests as well as on the level of proficiency in physics. In the case of indecisive students, when the choice was questionable, the teacher assigned them to a suitable team.

The teacher appointed a team leader who was in charge of distribution of reference materials and preparing the group for their role in the project and presentation on the given topic, as advised by Slavin [30,31] and Johnson and Johnson [32]. Each team consisted of approximately the same number of students and its size depended on the total number of students in a class (from 8 to 11 students per team). The aim was to encourage a discussion among the students' teams which would reveal the cognitive processes, emotions, and motivation.

This part of the research was initiated by a lecture given by Professor of Physics Ivica Puljak, Faculty of Electrical Engineering, Mechanical Engineering and Naval Architecture, University of Split, Croatia, a member of the Croatian research team at CERN. The lesson served to inform students about all the relevant facts of the CERN project to the extent to which the students were interested. The students were also given the opportunity and encouraged to ask questions. A significant interest in the project on behalf of a number of students was noticed, as well as lively communication with Professor Puljak.

The following eight sessions were dedicated to the presentation of the contents by the students' teams who used standard lecture mode aided by a number of visually rich PowerPoint ${ }^{\mathrm{TM}}$ presentations. The other students used their notebooks to record important information and particular characteristics of each experiment. No particular oral discussion among the students occurred in this phase of the project, although the teacher tried to encourage students' oral questions. Only the members of the "critique team" recorded all their questions and passed them in written form to the presenting teams. These questions were answered later in two discussion sessions. The seating arrangement was strictly set and it was the teacher-researcher who always conducted the session and controlled the classroom atmosphere.

Two of the last three project sessions were reserved for students of two presenting teams to answer the questions posed previously by the critique team. Finally, in the last session of the project, the critique team was asked to prepare and conduct a debate about all "open issues" which, according to them, were not treated conclusively. The debate triggered a number of interesting opinions about the project and the studied topics. 


\section{Experimenting and discussion}

ED pedagogy was utilized for a group of three physics sections (85 students) who were supposed to cover some classical physics topics in an active-learning way. As it is widely known, some of the sequential tasks which promote active learning are (1) predict-observe-explain [33] or (2) observe-explain-predict-test [34,35].

These physics learning sequences activate existing student knowledge and test it by comparing the predicted and the observed. These sequences of active learning were carried out by using simple experiments to treat a selection of physical phenomena for which students' alternative conceptions are well known [1,36-38]:

(a) force and the concept of motion (4 sessions),

(b) pressure (hydrostatic, hydraulic, atmospheric, hydrodynamic) (4 sessions),

(c) heat (4 sessions).

The teacher organized the teaching process in such a way that one simple experiment was carried out every session. At the beginning of each session an experiment was described to the students without actually carrying it out. The students were asked to predict the possible results of the experiment. Both the predicted results and their physical explanation had to be noted in their notebooks. Then they were asked to give their own personal explanations of the anticipated results. Once the possible results of the experiment were defined, i.e., when groups of students with the same "physical" views were formed, the students were able to debate and offer their explanations for the expected results. The debate allowed the students' preconceptions and the level of scientific reasoning to be clearly recognized by both the instructor and the students themselves.

After the debate, the experiment was conducted by the teacher and the results were observed and recorded. Surprising results of experiments always provoked students' delight and positive emotions. They often asked to repeat the experiment themselves because they did not believe the result was possible. Naturally, upon their request the students were allowed to carry out the experiment themselves. The experiments were followed by another debate based on the reasons for predicting certain results of the experiment. This discussion, guided and helped by the teacher, led to the construction of a better physical explanation of the observed phenomenon.

The seating arrangement was informal, in particular during the experiment itself. The students wanted to be as close as possible to the place where the experiment was being carried out and they were also given the opportunity to do it themselves.

We will present one example for each of the abovementioned sequences of active learning.

a. Predict-observe-explain: The smashed can experiment $\mathrm{The}$ lesson commenced with the description of the experiment to be conducted.
An empty soda can would be filled with water (about $0.3 \mathrm{dl}$ ). Then the can would be placed on a burner in order to bring the water to a boil. The water would be left to boil for 20-30 s, so that the interior of the can would be completely filled with hot steam.

In the meantime, while waiting for water to boil, a bowl with cold water would be prepared. Using a protective glove, the soda can would be taken from the burner and quickly dipped it into the cold water, upside down. The students had to predict: What will happen to the can when it is dipped into the cold water?

Most of the students predicted that, once the can was immersed into the cold water, it would slowly cool by letting the water slowly enter the can thus gaining thermodynamic balance. They compared it to throwing a hot stone or another solid body into the water, forgetting about the steam in the can.

Students knew from their personal experience that it takes a considerable force to smash a can. But when the experiment was conducted, the students saw, much to their surprise and amusement, the collapse of the can when it touched the cold water. The experiment was followed by students' explanation of the observed phenomenon. The teacher led the discussion using the following questions.

What force was responsible for the can collapse or deformation? What happened with the water in the can while it was getting hotter? What happens with steam when we dip the can in the cold water? What is the relationship between the pressure and temperature? What happens to the pressure in the can after the can is dipped into the cold water?

The students finally concluded that a sudden condensation of steam causes that pressure of the remaining steam to decrease dramatically (less steam-less pressure). This results in a difference between the inside and the outside pressure. This difference is large enough to smash the can.

b. Observe-explain-predict-test: Air- and water-filled balloons over the candle flame The session commenced by inflating a balloon with air. The students were asked what would happen if a candle flame was brought close to the surface of the balloon.

Their daily experience with balloons suggests to them that the balloon will explode. The "observe" phase was carried out to confirm that their answer based on their experience is correct. They could see the result of the experiment: the candle flame burned a small hole in the balloon and the air quickly escaped with a burst. In the "explain" phase, the students were asked to explain what they observed. After much discussion, the students developed this explanation: "The heat is quickly transferred into the balloon because the rubber is stretched thin. With air inside the balloon, this heat is not readily dissipated away from the spot touching the flame. That's why the balloon partially melts or burns, then quickly bursts." 
TABLE III. Gender information for groups surveyed.

\begin{tabular}{lccc}
\hline \hline & All students & RPQ group & ED group \\
\hline Females & $110(63 \%)$ & $56(62 \%)$ & $54(64 \%)$ \\
Males & $66(37 \%)$ & $35(38 \%)$ & $31(36 \%)$ \\
Overall & $176(100 \%)$ & $91(100 \%)$ & $85(100 \%)$ \\
\hline \hline
\end{tabular}

In the next, "predict," phase of the sequence, the balloon was filled with water and the students were asked to answer the question: What will happen if the candle flame is brought close to the surface of the balloon? Class discussion led to the prediction that the balloon would burst again because the rubber will again touch fire and it would burn letting the water leak from the balloon.

The experiment was conducted and students' reactions observed. The students were surprised with the outcomethe balloon did not burst.

The experiment allowed students to test their predictions and finally dismiss them, but also to conclude that water has a higher specific heat capacity than air. Since the students were familiar with the concept of heat capacity, the experiment provided the opportunity for them to test the previously acquired knowledge and visualize the extent to which the specific heat of water is much higher than the specific heat of air. Within this session the students were also able to test their ideas about the following problem: Can water reach the boiling point in a paper cup? This was a further simple example that enabled students to test their acquired knowledge.

In the course of the project, students participated gladly in situations enabling them to obtain new knowledge. They also recognized those situations in everyday life, which make possible a positive shift in their previous conceptions and knowledge. Student discussions about the physical phenomena observed in the classroom were also noticed in out-of-class situations.

The students who did not actively participate in regular physics classes often showed a great improvement in active learning sessions. We found that the students were able to direct the learning process themselves by their reactions and answers, and to seek improvement of their initial answers without fearing bad grades or reprimands.

C. Gender characteristicsOut of the total number of students who took part in the research (176), there were 110 females and 66 males. The total number is broken down into two groups for the purpose of the experiment. The RPQ group consists of 91 students altogether, out of which 56 are female and 35 are male, while the ED group consists of 85 students, out of which 54 are female and 31 are male (Table III).

\section{CLASS TEST APPLICATION}

The research task was to measure how two different methods of physics learning affect students' attitudes toward physics and beliefs about physics learning. In this study, we used a modified version of the Colorado Learning Attitudes about Science Survey (CLASS v3) [7] which asks students to respond to each statement with both their personal belief and the response they thought a physicist would give [8].

The CLASS was administered at the beginning of the semester (pretest) and again in the last week of the semester (posttest). The CLASS survey consists of 42 statements to which students respond using a 5-point Likert scale. The use of a 5-point Likert scale (strongly disagree to strongly agree) is important for validity and scoring. For example, students' interpretations of agree versus strongly agree are not consistent (it may not result in the same selection). One student may respond with agree while another student responds with strongly agree. Complete details of the design, categorization, validation, and scoring of the CLASS are described by Adams et al. [7]. Scoring is done by determining the percentage of responses for each student (for which the student agrees with the experts' view) and then averaging these individual scores to determine the average percent favorable. Briefly, the student's "overall" percent favorable belief score is equal to the percentage of statements for which their response agrees with that of an expert physicist. Scoring is typically provided as "overall" and for 8 separate categories (see the Table V below). Each category consists of 4-8 statements that characterize a specific aspect of student thinking. Together, these categories include 27 of the statements that are scored. The overall score includes these statements plus an additional 9 statements.

In what follows, we will analyze the overall results of the CLASS test for all surveyed students, overall pre-CLASS and post-CLASS test results for each group, as well as the results by category. All evaluated students submitted valid pre-CLASS and post-CLASS tests so all data are matched and represent $100 \%$ of the students in the courses.

Pre-CLASS and post-CLASS results included in the study are presented in Table IV and Fig. 1.

Pre-CLASS results of "personal beliefs" about nature of physics and physics learning (for the RPQ group 51.4\%, for the ED group 50.3\%) are in accord with previously published results $[7-9,11]$. The pre-CLASS results for the attitude toward related "physicists' beliefs" (comparing students ideas about what physicists believe to what a group of physicists actually responded to the survey) are comparable to the results at the University of Colorado (Boulder) which amount to $80 \%$ [8]. It means they are not significantly different from the results of our study. For the RPQ group they are $79.1 \%$ while for ED group they are $77.0 \%$.

Looking at students' "physicist" scores we notice they are more expertlike than their "personal" scores. It seems that, while students may be relatively well acquainted with what physicists believe about physics and learning physics, they themselves do not agree with physicists' ideas. Thus physicists' ideas do not apply to their own personal contact 
TABLE IV. Overall favorable scores on pre-CLASS and post-CLASS test for RPQ and ED group [standard error in parentheses; large shifts $(p<0.05)$ in bold font].

\begin{tabular}{lllllllr}
\hline \hline & & & Personal & & & Physicist \\
& & Pre $(\%)$ & Post $(\%)$ & \multicolumn{1}{c}{ Shift $(\%)$} & Pre $(\%)$ & Post (\%) & Shift (\%) \\
\hline RPQ group $(N=91)$ & Overall & $51.4(2.6)$ & $57.2(2.8)$ & $\mathbf{5 . 8}(0.8)$ & $79.1(1.3)$ & $86.9(1.1)$ & $\mathbf{7 . 8}(0.8)$ \\
& Females & $49.8(3.7)$ & $52.4(3.7)$ & $\mathbf{2 . 5}(0.8)$ & $83.1(1.4)$ & $88.7(1.0)$ & $\mathbf{5 . 6}(0.6)$ \\
& Males & $53.7(3.5)$ & $64.9(3.8)$ & $\mathbf{1 1 . 2}(1.1)$ & $72.5(2.3)$ & $84.0(2.3)$ & $\mathbf{1 1 . 4}(1.5)$ \\
ED group $(N=85)$ & Overall & $50.3(2.5)$ & $75.8(2.4)$ & $\mathbf{2 5 . 6}(1.2)$ & $77.0(1.2)$ & $92.5(0.8)$ & $\mathbf{1 5 . 5}(0.7)$ \\
& Females & $46.5(3.1)$ & $72.6(2.9)$ & $\mathbf{2 6 . 1}(1.6)$ & $78.9(1.6)$ & $92.8(1.1)$ & $\mathbf{1 3 . 9}(0.8)$ \\
& Males & $56.8(4.1)$ & $81.4(3.9)$ & $\mathbf{2 4 . 6}(1.7)$ & $73.7(1.8)$ & $91.9(1.3)$ & $\mathbf{1 8 . 2}(1.1)$ \\
\hline \hline
\end{tabular}

with physics and the strategies they use in learning physics and solving physics problems.

Change in the personal beliefs in the RPQ group was $5.8 \%$, and in the ED group was $25.6 \%$. In attitude toward physicists' beliefs the change for the RPQ group was 7.8\%, and for the ED group was $15.5 \%$.

Observing the pre-CLASS and post-CLASS results by gender in Table IV, we can see that in both groups females show a better perception of physicists' beliefs but do not see these beliefs to be true for themselves. Males, on the other hand, have slightly higher personal attitudes than the females, while their perception of physicists is poorer than the females' perceptions. These results are similar to previous results, which show that CLASS scores are lower for females' personal beliefs than males. The same result was repeated at posttest in both groups. These results are consistent with U.S. students who also have a larger personal physicist gap for females than for males [7,8].

A particularly interesting fact is that in the RPQ group we notice a greater improvement in the attitude physicist (7.8\%) than in personal attitudes $(5.8 \%)$. The females of the RPQ group contribute to the result with $2.5 \%$ in personal attitudes and $5.6 \%$ in physicist attitude. On the other hand, we have a completely different situation with the males of the RPQ group who greatly improve their

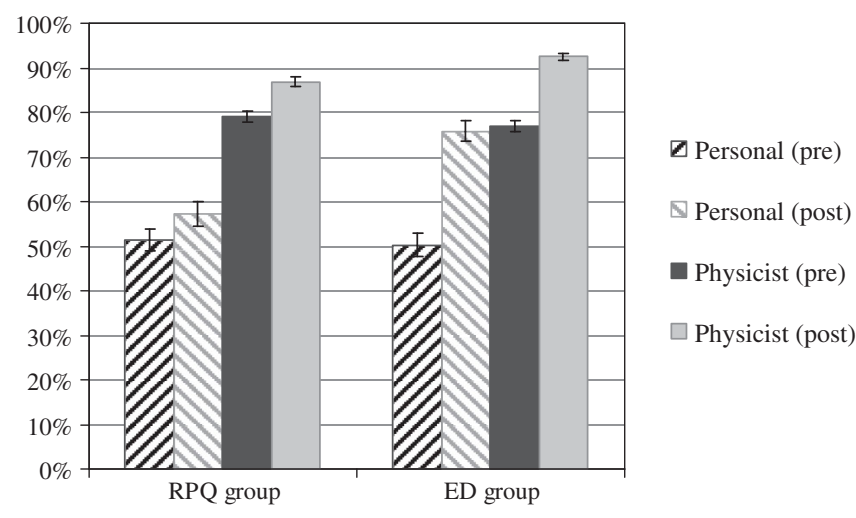

FIG. 1. Overall favorable scores on pre-CLASS and postCLASS test for RPQ group and ED group. personal attitudes by $11.2 \%$, while the physicist attitude is improved by statistically significant $11.4 \%$.

In the ED group, a statistically significant improvement in personal views has been achieved both with females $(26.1 \%)$ and with males (24.6\%). In the section of the table labeled "physicist," males achieve a significant improvement $(18.2 \%)$, while the improvement for the females is also statistically relevant, but somewhat lower (13.9\%). While males in this group provide $73.7 \%$ of favorable responses to the pretest, females achieved $78.9 \%$ of favorable responses. At posttest all students show a very good perception of what physicists believe $(92.8 \%$ females, males $91.9 \%$ ).

The important fact is that both groups made progress in the CLASS test both in personal attitude as well as in physicist attitude.

Overall scores for the RPQ and ED groups of students by categories of the CLASS test for personal attitude are shown in Table V and Fig. 2.

The Table V data show that the personal results for the RPQ group and the ED group at the pretest are not equivalent, but are significantly different in some of the categories. The RPQ group achieves $48.0 \%$ of favorable results in the personal interest category while the ED group achieves $54.1 \%$; in the category problem solving general, the RPQ group gains $58.1 \%$ while the ED group gains $52.9 \%$ of favorable results. The problem solving confidence category also displays important difference in the pretest results. While the RPQ group has $65.9 \%$ of favorable results, the ED group has a lower score, $60.6 \%$. The problem solving sophistication category also shows the difference between the groups on the pretest: $43.6 \%$ for the RPQ group and $36.7 \%$ for the ED group. The noticed differences between the groups make it even more important to observe the gains for both groups of students at the posttest.

Table V shows that for the RPQ group of students category shifts are within the range from statistically insignificant $-1.1 \%$ (problem solving confidence) to statistically significant $7.1 \%$ (conceptual connections), while in the ED group the shift ranged from statistically significant $20.3 \%$ (problem solving confidence) to the significant $26.5 \%$ (problem solving sophistication).

The students of the RPQ group achieved a statistically significant positive shift in the categories of personal 
TABLE V. Scores "personal" by category of pre-CLASS and post-CLASS test for RPQ and ED group [standard error in parentheses; large shifts $(p<0.05)$ in bold font].

\begin{tabular}{|c|c|c|c|c|c|c|}
\hline \multirow[b]{2}{*}{ Category } & \multicolumn{3}{|c|}{ RPQ group personal $(N=91)$} & \multicolumn{3}{|c|}{ ED group personal $(N=85)$} \\
\hline & Pre $(\%)$ & Post $(\%)$ & Shift $(\%)$ & Pre $(\%)$ & Post $(\%)$ & Shift $(\%)$ \\
\hline All categories & $51.2(2.9)$ & $55.5(3.2)$ & $4.3(0.8)$ & $50.8(3.0)$ & $75.0(2.6)$ & $24.2(1.3)$ \\
\hline Real world connection & $62.6(3.7)$ & $63.7(3.6)$ & $1.1(2.2)$ & $62.9(3.6)$ & $89.1(2.5)$ & $26.2(2.5)$ \\
\hline Personal interest & $48.0(3.4)$ & $54.0(3.5)$ & $6.0(1.5)$ & $54.1(3.4)$ & $76.5(3.1)$ & $22.4(2.2)$ \\
\hline Sense making or effort & $54.5(3.0)$ & $59.0(3.2)$ & $4.6(1.2)$ & $54.6(3.2)$ & $75.3(3.0)$ & $20.7(2.0)$ \\
\hline Conceptual connections & $47.6(3.4)$ & $54.8(3.6)$ & $7.1(1.4)$ & $47.5(3.7)$ & $68.4(3.0)$ & 21.0 \\
\hline Applied conceptual understanding & $42.2(3.1)$ & $48.5(3.5)$ & $6.3(1.3)$ & $40.0(3.2)$ & $66.1(3.1)$ & $26.1(1.9)$ \\
\hline Problem solving general & $58.1(3.3)$ & $58.0(3.3)$ & $-0.1(1.5)$ & $52.9(2.9)$ & $75.9(2.6)$ & $22.9(1.5)$ \\
\hline Problem solving confidence & $65.9(4.0)$ & $64.8(3.6)$ & $-1.1(1.9)$ & $60.6(3.4)$ & $80.9(2.9)$ & $20.3(2.2)$ \\
\hline Problem solving sophistication & $43.6(3.1)$ & $49.3(3.4)$ & $5.7(1.4)$ & $36.7(3.3)$ & $63.1(3.1)$ & $26.5(2.1)$ \\
\hline
\end{tabular}

interest $(6.0 \%)$, sense making or effort $(4.6 \%)$, conceptual connections $(7.1 \%)$, applied conceptual understanding (6.3\%), and problem solving sophistication (5.7\%), while in the categories real world connection, problem solving general, and problem solving confidence there are no statistically significant shifts on the posttest.

The ED group of students achieved a statistically significant positive shift in all categories of the CLASS test: real world connection $(26.2 \%)$, personal interest $(22.4 \%)$, sense making or effort (20.7\%), conceptual connections (21.0\%), applied conceptual understanding (26.1\%), problem solving general $(22.9 \%)$, problem solving confidence $(20.3 \%)$, and problem solving sophistication $(26.5 \%)$.

The results of CLASS by categories for the RPQ group and the ED group of students in relation to gender are given in Tables VI and VII.

The data in Table VI show that in the RPQ group in the category real world connection neither males nor females show any significant change in the personal views. Both sexes show similar positive shifts in the categories of personal interest (females 6.3\%, males 5.7\%) and conceptual connections (females $7.4 \%$, males $6.7 \%$ ). Males have significant gains in categories sense making or effort (females $2.8 \%$, males $7.3 \%$ ), applied conceptual understanding (females $3.8 \%$, males $10.2 \%$ ), and problem solving sophistication (females $4.5 \%$, males $7.6 \%$ ). In the categories of problem solving general and problem solving confidence the females realized the negative shift of $-5.4 \%$, and the males have a positive shift in both categories, $8.2 \%$ in problem solving general and $5.7 \%$ in problem solving confidence.

The data in Table VII show that in the ED group both males and females achieve positive change in all categories. Males' progress ranges from $13.8 \%$ (sense making or effort) to $25.3 \%$ (applied conceptual understanding). Females show greater progress than males in all categories and that progress ranges from $20.8 \%$ (problem solving confidence) to $29.3 \%$ (problem solving sophistication).

The study included a small group of students. Nonetheless, the basic interpretation of the data obtained

\section{CLASS pre and post: $R P Q$ group}

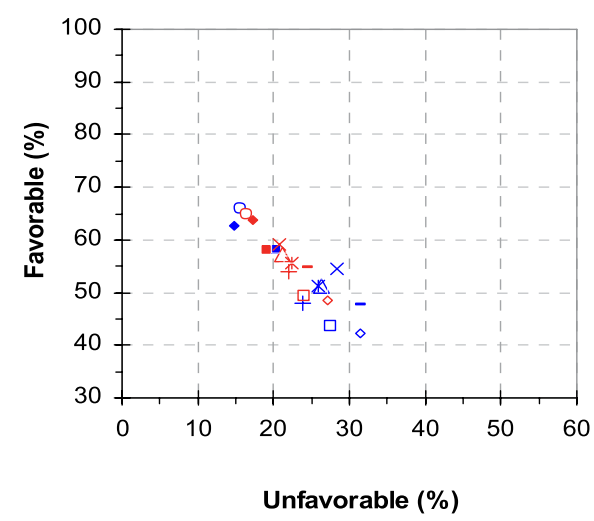

CLASS pre and post: ED group

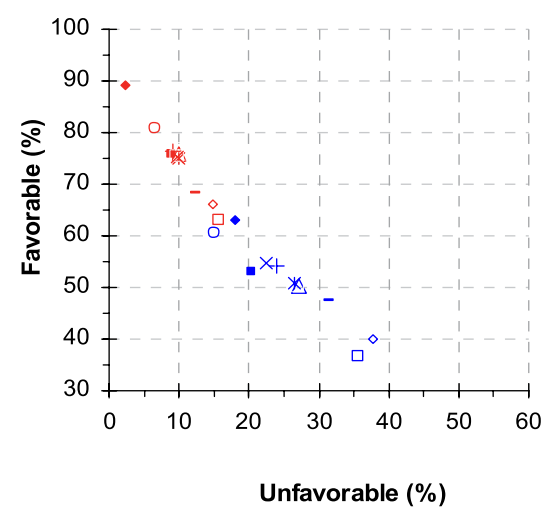

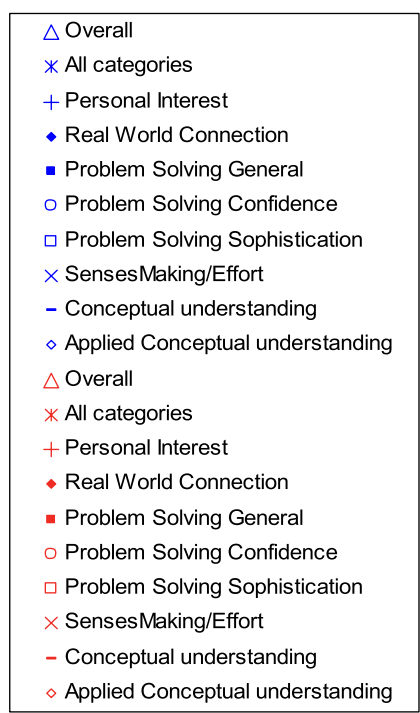

FIG. 2 (color online). Overall scores and scores "personal” by category on pre-CLASS and post-CLASS test for RPQ group and ED group. 
TABLE VI. Relationships between all categories and gender for RPQ group in pre-CLASS and post-CLASS test [standard error in parentheses; large shifts $(p<0.05)$ in bold font].

\begin{tabular}{|c|c|c|c|c|c|c|}
\hline \multirow[b]{3}{*}{ Category } & \multicolumn{6}{|c|}{ RPQ group personal } \\
\hline & \multicolumn{3}{|c|}{ Females $(N=56)$} & \multicolumn{3}{|c|}{ Males $(N=35)$} \\
\hline & Pre $(\%)$ & Post $(\%)$ & Shift $(\%)$ & Pre $(\%)$ & Post $(\%)$ & Shift $(\%)$ \\
\hline All categories & $47.2(4.0)$ & $49.1(4.2)$ & $1.9(1.0)$ & $57.7(3.9)$ & $65.7(4.2)$ & $\mathbf{8 . 0}(1.3)$ \\
\hline Real world connection & $59.4(5.1)$ & $58.5(5.0)$ & $-0.9(2.7)$ & $67.9(5.0)$ & $72.1(4.4)$ & $4.3(3.7)$ \\
\hline Personal interest & $41.1(4.5)$ & $47.3(4.6)$ & $6.3(2.0)$ & $59.0(4.5)$ & $64.8(4.7)$ & $5.7(2.2)$ \\
\hline Sense making or effort & $47.7(3.9)$ & $50.5(4.1)$ & $2.8(1.4)$ & $65.3(4.2)$ & $72.7(4.4)$ & $7.3(2.3)$ \\
\hline Conceptual connections & $38.1(4.4)$ & $45.5(4.7)$ & $7.4(1.8)$ & $62.9(4.4)$ & $69.5(4.5)$ & $6.7(2.4)$ \\
\hline Applied conceptual understanding & $37.5(4.2)$ & $41.3(4.6)$ & $3.8(1.4)$ & $49.8(4.2)$ & $60.0(4.8)$ & $10.2(2.4)$ \\
\hline Problem solving general & $59.4(4.5)$ & $54.0(4.5)$ & $-5.4(1.9)$ & $56.1(4.7)$ & $64.3(4.5)$ & $8.2(2.0)$ \\
\hline Problem solving confidence & $66.5(5.3)$ & $61.2(4.8)$ & $-\mathbf{5 . 4}(2.3)$ & $65.0(5.9)$ & $70.7(5.3)$ & $5.7(2.7)$ \\
\hline Problem solving sophistication & $39.9(4.3)$ & $44.3(4.5)$ & $4.5(1.9)$ & $49.5(4.2)$ & $57.1(4.8)$ & $7.6(2.2)$ \\
\hline
\end{tabular}

TABLE VII. Relationships between all categories and gender for ED group in pre-CLASS and post-CLASS test [standard error in parentheses; large shifts $(p<0.05)$ in bold font].

\begin{tabular}{|c|c|c|c|c|c|c|}
\hline \multirow[b]{3}{*}{ Category } & \multicolumn{6}{|c|}{ ED group personal } \\
\hline & \multicolumn{3}{|c|}{ Females $(N=54)$} & \multicolumn{3}{|c|}{ Males $(N=31)$} \\
\hline & Pre $(\%)$ & Post $(\%)$ & Shift $(\%)$ & Pre $(\%)$ & Post $(\%)$ & Shift $(\%)$ \\
\hline All categories & $44.9(3.6)$ & $71.2(3.2)$ & $26.3(1.8)$ & $61.0(4.7)$ & $81.6(4.3)$ & $20.6(1.7)$ \\
\hline Real world connection & $57.9(4.3)$ & $86.6(3.3)$ & $28.7(3.0)$ & $71.8(6.1)$ & $93.5(3.5)$ & $21.8(4.5)$ \\
\hline Personal interest & $47.2(4.2)$ & $72.8(4.2)$ & $25.6(2.9)$ & $66.1(5.3)$ & $82.8(4.5)$ & $16.7(2.9)$ \\
\hline Sense making or effort & $47.1(3.7)$ & $71.7(3.7)$ & $24.6(2.5)$ & $67.7(5.3)$ & $81.6(5.0)$ & $13.8(2.6)$ \\
\hline Conceptual connections & $38.3(4.4)$ & $63.0(3.5)$ & $24.7(2.7)$ & $63.4(5.8)$ & $78.0(4.9)$ & $14.5(2.6)$ \\
\hline Applied conceptual understanding & $33.9(3.9)$ & $60.3(3.7)$ & $26.5(2.5)$ & $50.7(5.0)$ & $76.0(5.3)$ & $25.3(2.5)$ \\
\hline Problem solving general & $48.8(3.6)$ & $73.1(3.3)$ & $24.3(1.9)$ & $60.1(4.5)$ & $80.6(4.1)$ & $20.6(2.4)$ \\
\hline Problem solving confidence & $57.9(4.3)$ & $78.7(3.6)$ & $20.8(2.7)$ & $65.3(5.5)$ & $84.7(4.9)$ & $19.4(3.7)$ \\
\hline Problem solving sophistication & $28.7(3.9)$ & $58.0(3.6)$ & $29.3(2.9)$ & $50.5(5.3)$ & $72.0(5.5)$ & $21.5(2.7)$ \\
\hline
\end{tabular}

by the CLASS test showed a significant shift of students towards a more professional attitude in physics in both observed groups.

\section{DISCUSSION}

The RPQ group of students are fascinated by physicists' efforts in understanding new concepts which seems to be the reason for a better progress in "physicist" than in the "personal" attitude. Moreover, in this group males' attitudes are far better improved than the females'. Most likely, males' improvement of attitudes was triggered by interesting and technologically complex experiments which help them to make sense of implementation of physical knowledge in the study of nature. The lack of progress in the RPQ groups in the category real world connection might be the result of analyzing the technologically demanding physical experiments aimed at verifying the new physical theories. These theories are very complicated for students and very isolated from their everyday experiences. Namely, although the students obtain information about the new findings, they can hardly encounter them in their daily environment. Personal interest in new scientific knowledge among students of the RPQ group was considerable, although the theoretical basis of such knowledge is extremely complicated, both in terms of mathematical derivations and argumentations and physical explanations. Students' interest in the scientific topics is most likely the result of the presence of such topics in media where they are frequently discussed. Regardless of the fact that the RPQ group of students find contemporary physics concepts relatively interesting, their attitude about the sense of effort in teaching physics did not achieve a progress as high as in the ED group. Of course, regardless of student effort invested, the concepts that support the new findings of physical science often remain vague and complicated for them. After the project, students of the RPQ group alter the attitudes and beliefs about conceptual relationships. We find this surprising because most of these students were exposed to the concepts that, for their full understanding, require knowledge they do not possess. Teaching physics in the RPQ group has not managed to strengthen students' beliefs and attitudes towards the general problem solving at the group level. It has not managed to increase the level of personal confidence in dealing with problems, either. However, in these two categories there is a significant difference in the attitudes between males and females. While the females achieve a negative shift, the 
males achieve a positive shift. It is interesting that a positive overall shift is achieved in the category of problem solving sophistication, to which both males and females contribute with positive results.

Independently of the shifts in individual categories, the results indicate that with this instructional intervention, based on reading, presenting, and questioning, students generate an overall positive shift in the personal views.

Important gains in the ED group in the category of real world connection are the result of active learning experiences with simple experiments. A direct consequence of this teaching method is the ability to apply the experiments in everyday experiences and increased ability to identify physical concepts in a variety of phenomena. Considerable progress in the category of personal interest in this group is the result of teaching which involves conducting experiments with surprising outcomes and insisting on their interpretation. The articulate presentation of physical concepts in simple experiments enhanced their acquisition. This group of students recognizes the fact that, by investing some hard work, they manage to understand the physical concepts presented and are able to find their application in everyday life. This gives further sense to the efforts made. The ED group of students, in the search for answers to the outcome of the experiment and in the attempt to define their attitudes, build conceptual connections and make use of conceptual understanding. This process can often go awry, but the discussion with colleagues and teachers and the recognition of concepts in everyday phenomena help students to make corrections within their thinking process, build better conceptual connections, and apply conceptual understanding. These results indicate that the physics teaching through active learning, implementing the sequences (1) predict-observe-explain or (2) observeexplain-predict-test, suits students and increases their interest both in learning physics and in physics knowledge as a constituent part of understanding phenomena encountered in everyone's life.

Based on the previous study results that show decreases in students' scores for reformed and traditional classes $[4,12,14]$, we assumed that the same would apply to this context. However, in light of the rather large gains shown for the ED curriculum and the surprising results shown for the RPQ curriculum, it would be interesting to question this assumption. This might be the main topic of one of the following studies and can be carried out by collecting CLASS scores from similar students in a traditional physics course.

\section{CONCLUSIONS}

Information presented in this paper shows the CLASS shifts and the nature of these changes, which were induced by two forms of learning: reading, presenting, and questioning (RPQ) and experimenting and discussion (ED).
The teacher who carried out the project (the first author) tried to be as objective as possible in order not to influence the results of the learning process in experimental groups of students.

There are three more aspects that deserve further comments. First, these data indicate two good models to improve students' attitudes and beliefs in high school physics lessons. Although neither of the two observed forms of learning physics included topics from nature of science, it is important to emphasize that students might deal with these issues, either explicitly or implicitly, within other school subjects in their curricula in Croatian high schools. Positive changes achieved by the RPQ group are comparable with the results of the CLASS test in courses, which include the nature of science (e.g., PET curriculum) [12], while the results are significantly better in the ED group.

The second aspect worth commenting on is that the data show the significant progress of students in building positive attitudes within only one semester of teaching high school physics (twelve 45-min sessions), which is in accordance with the results of other similar studies [20].

The third aspect is the fact that these two methods help both females and males achieve positive shifts in the CLASS test. Nevertheless, males seem to benefit more from the RPQ method while in the ED method the gains for males and females are comparable, which makes this method more suitable because of its potential impact on females' interest in physics.

In conclusion, both groups of students showed statistically significant positive shifts in their attitudes and beliefs toward physics and in their understanding of physicists' attitudes and beliefs toward physics. While the RPQ group showed statistically significant positive shifts in five of the eight categories, and no statistically significant negative shift in any of the categories, the ED group showed statistically significant positive shifts in all of the CLASS categories.

Although the study compares the respective gains of the two methods, a dose of caution should be exercised because the groups differ not only in the method of learning but also in the topics studied. It could be the aim of a future study to compare both methods of learning (reading about physical concepts or acquiring physical concepts by doing physics) dealing with the same physics topics.

\section{ACKNOWLEDGMENTS}

We thank Professor Mladen Buljubašić, Ministry of Education coordinator for physics, for granting the permission for using up to a quarter of the annual syllabus (16 lessons) for the project. We thank Professor R. Hake, Professor D. Dykstra, and Professor Z. Hrepic for their kind help and thoughtful advice in finishing this paper. We also want to thank Professor S. Pivac for the great support and effort she put into processing data. 
[1] D. Hammer, Epistemological beliefs in introductory physics, Cogn. Instr. 12, 151 (1994).

[2] L. Lising and A. Elby, The impact of epistemology on learning: A case study from introductory physics, Am. J. Phys. 73, 372 (2005).

[3] D. Hammer, Student resources for learning introductory physics, Am. J. Phys. 68, S52 (2000).

[4] E.F. Redish, J. M. Saul, and R. N. Steinberg, Student expectations in introductory physics, Am. J. Phys. 66, 212 (1998).

[5] I. Halloun and D. Hestenes, Interpreting VASS dimensions and profiles for physics students, Sci. Educ. 7, 553 (1998). A description of VASS is available at http://modeling.la .asu.edu/R\&E/IHalloun/VASS-P204_June04.pdf.

[6] A. Elby, J. Fredriksen, C. Schwarz, and B. White, http://www2.physics.umd.edu/ elby/EBAPS/EBAPS_items .htm.

[7] W. K. Adams, K. K. Perkins, N. S. Podolefsky, M. Dubson, N. D. Finkelstein, and C.E. Wieman, New instrument for measuring student beliefs about physics and learning physics: The Colorado Learning Attitudes about Science Survey, Phys. Rev. ST Phys. Educ. Res. 2, 010101 (2006).

[8] K.E. Gray, W. K. Adams, C.E. Wieman, and K. K. Perkins, Students know what physicists believe, but they don't agree: A study using the CLASS survey, Phys. Rev. ST Phys. Educ. Res. 4, 020106 (2008).

[9] W. K. Adams, K. K. Perkins, M. Dubson, N.D. Finkelstein, and C.E. Wieman, The Design and Validation of the Colorado Learning Attitudes About Science Survey, in Proceedings of the Physics Education Research Conference 2004 (AIP, Melville, NY, 2005), Vol. 790, pp. 45-48.

[10] N. G. Lederman, F. Abd-El-Khalick, R. L. Bell, and R. Schwartz, Views of Nature of Science questionnaire: Toward valid and meaningful assessment of learners' conceptions of Nature of Science, J. Res. Sci. Teach. 39, 497 (2002).

[11] K. K. Perkins, W. K. Adams, S. J. Pollock, N. D. Finkelstein, and C. E. Wieman, Correlating student beliefs with student learning using the Colorado Learning Attitudes about Science Survey, AIP Conf. Proc. 790, 61 (2005).

[12] V. K. Otero and K. E. Gray, Attitudinal gains across multiple universities using the Physics and Everyday Thinking curriculum, Phys. Rev. ST Phys. Educ. Res. 4, 020104 (2008).

[13] R. Thornton and D. Sokoloff, Assessing student learning of Newton's laws: The Force and Motional Conceptual Evaluation and the Evaluation of Active Learning Laboratory and Lecture Curricula, Am. J. Phys. 66, 338 (1998).

[14] S. J. Pollock, Transferring transformations: Learning gains, student attitudes, and the impacts of multiple instructors in large lecture courses, AIP Conf. Proc. 818, 141 (2006).

[15] L. Bao, T. Cai, K. Koenig, K. Fang, J. Han, J. Wang, Q. Liu, L. Ding, L. Cui, Y. Luo, Y. Wang, L. Li, and N. Wu, Learning and scientific reasoning, Science 323, 586 (2009).
[16] Z. Hrepic, P. Adams, J. Zeller, N. Talbott, G. Taggart, and L. Young, Developing an inquirybased physical science course for preservice elementary teachers, AIP Conf. Proc. 818, 121 (2006).

[17] C. Mamolo and S. Rebello, Learning and dynamic transfer using the 'Constructing Physics Understanding' (CPU) curriculum: A case study, AIP Conf. Proc. 883, 77 (2007).

[18] F. Abd-El-Khalick, Embedding Nature of Science instruction in preservice elementary science courses: abandoning scientism, but ..., J. Sci. Teach. Educ. 12, 215 (2001).

[19] V. Otero and K. Gray, Learning to think like scientists with the PET curriculum, in Proceedings of the 2007 Physics Education Research Conference, edited by L. McCullough, J. Hsu, and P. Heron (AIP, Melville, NY, 2007), pp. 160-163.

[20] E. Brewe, L. Kramer, and G. O'Brien, Modeling instruction: Positive attitudinal shifts in introductory physics measured with CLASS, Phys. Rev. ST Phys. Educ. Res. 5, 013102 (2009).

[21] V.L. Akerson, F. Abd-El-Khalick, and N. G. Lederman, Influence of a reflective explicit activity based approach on elementary teachers' conceptions of Nature of Science, J. Res. Sci. Teach. 37, 295 (2000).

[22] V. Paar, Physics 4-Coursebook for 4th Grade of Grammar Schools (Školska knjiga, Zagreb, 2006).

[23] S. M. Glynn and K. D. Muth, Reading and writing to learn science: Achieving scientific literacy, J. Res. Sci. Teach. 31, 1057 (1994).

[24] V.R. Gillis and G. MacDougall, Reading to learn science as an active process, Sci. Teach. 74, 45 (2007).

[25] R. Bleicher, High school students presenting science: An interactional sociolinguistic analysis, J. Res. Sci. Teach. 31, 697 (1994).

[26] B. Daley, A project-based approach: Students describe the physics in movies, Phys. Teach. 42, 41 (2004).

[27] C. Chin, D. E. Brown, and B. C. Bruce, Student-generated questions: A meaningful aspect of learning in science, Int. J. Sci. Educ. 24, 521 (2002).

[28] C. Chin and L. G. Chia, Problem-based learning: Using students' questions to drive knowledge construction, Sci. Educ. 88, 707 (2004).

[29] C. Chin and J. Osborne, Students' questions: A potential resource for teaching and learning science, Stud. Sci. Educ. 44, 1 (2008).

[30] R.E. Slavin, in Interaction in Cooperative Groups, R. Hertz-Lazarowitz and Miller (Cambridge University Press, New York, 1992).

[31] R.E. Slavin, Research on cooperative learning and achievement: What we know, what we need to know, Contemp. Educ. Psychol. 21, 43 (1996).

[32] D. Johnson and R. Johnson, Learning Together and Alone: Cooperative, Competitive and Individualistic Learning (Allyn \& Bacon, Boston, 1999).

[33] R. White and R. Gunstone, Probing Understanding (Falmer Press, London, 1992), Chap. 3.

[34] E. Etkina, A. Van Heuvelen, D. T. Brookes, and D. Mills, Role of experiments in physics instruction: A process approach, Phys. Teach. 40, 351 (2002). 
[35] A. Van Heuvelen and E. Etkina, The Physics Active Learning Guide (Addison Wesley, San Francisco, 2006), Instructor's edition.

[36] J. Clement, Using bridging analogies and anchoring intuitions to deal with students' preconceptions in physics, J. Res. Sci. Teach. 30, 1241 (1993).
[37] L.C. McDermott and E.F. Redish, Resource Letter: PER-1: Physics Education Research, Am. J. Phys. 67, 755 (1999).

[38] H. Pfundt and R. Duit, Bibliography-Students Alternative Frameworks and Science Education (Institute for Science Education, Kiel, 2006). 